\title{
Study on Application of Goaf Management and Residual Mining Technology in Niujuan Deposit
}

\author{
Pan-xue Feng ${ }^{1,2, *}$, Dan Huang ${ }^{1}$ \\ ${ }^{1}$ Sub-Institute of Mining Engineering, Beijing General Rsearch Institute of Mining \& Metallurgy, Beijing 102600, China \\ ${ }^{2}$ School of Civil and Environmental Engineering, University of Science and Technology Beijing, Beijing 100083, China
}

\begin{abstract}
For goaf group and high grade embedded residual ore in NO.I ore body, the overall technical idea of pre-filling the key goaf, the residual mining and the non-key goaf filling is used. The goaf management was mainly based on waste rock filling and supplemented with cemented filling, which formed safe mining environment in the upper, lower isolation belts and efficient management in hidden danger goaf. For rib pillars with cemented rock filling and waste stone filling on both sides of goaf, the method of upward horizontal common layered and small layered filling with pointed pillars were employed respectivly. For the crown pillar overlying high strength of filling body and waste rock, the united method of upward horizontal layered filling with entrance filling and caving are separately employed. Regional and local multidimensional integrated monitoring system were built subsequently. Then, relevant technical safety measures were taken. This study is to achieve the goal of safe, efficient and economical goaf management and residual mining.
\end{abstract}

\section{Introduction}

Niujuan Silver-Gold Deposit belongs to inclined medium thick ore body. It is mined from surface to underground. NO. I ore body is the main mining target of Niujuan Silver-Gold Deposit. For short-hole shrinkage mining method that was mainly applied previously, a large number of irregular goafs with varying sizes and uneven height were currently formed in the level of No.I ore body 1190,1150 and 1110 . The total volume of the goaf is about $500,000 \mathrm{~m}^{3}$. With the mining of lower orebody, the underground goaf gradually increased, and it was the major hazard for mine safety production ([5]).

Meanwhile, a lot of high-grade rib pillars and crown pillars were left in goaf. The quantity of resource was about $470,000 \mathrm{~T}$. NO. I ore body was found with a larger value of mining and good economic benefits on reclamation. In addition, part of goafs was filled with waste rock more or less so as to ensure the stability of the stope. However, waste rock that existing in the form of dispersion will cause adverse effects on late residual mining.

Therefore, the study on goaf management and residual mining is rather essential to protect the safe production in stope and realize fully recycling of resources.

\section{The Overall Technical Ideas}

\subsection{Overview}

Currently, the goaf and ore pillar have formed framework of regional stability ([12]). Residual mining should destroy the balance of the original structure. Thus, the key goaf (unstable goaf) should be first filled, which could avoid causing chain-catastrophe due to the instability of partial goaf ([6],[13]). Secondly, reclamation should based on eliminating risks in key goaf and ensuring the overall stability of the stope ([1], [15]).

The method of filling was mainly applied in goaf management and residual mining. The treatment scheme of goaf mainly adopted waste rock filling and supplemented with cemented filling. If waste rock filling was employed overall, it could achieve the recycling of surface waste rock resources and keep waste rock under mines, and then minimize the cost of filling ([11]). If cemented filling was applied partially, it could achieve the reconstruction of the residual mining environment, and then meet the requirement of residual resources recovery $([16])$.

\subsection{Filling Sequence and Goal}

Fillings were sorted as key filling and non-key goaf filling. Among them, the key goaf was unstable goaf, which was determined mainly by Mathews stability 
analysis and numerical simulation of Fast Lagrangian Analysis of Continua (FLAC3D) ([3], [14]). Non-key goaf was beyond key goaf. Its filling sequence coordinated with residual mining. However, for the safety of mining, non-key goaf should be filled accordingly before each district started mining ([4]).

The open-pit was in the upper part of $1190 \mathrm{~m}$ level, and open-pit mining was completed. Regular production was operating currently below $1110 \mathrm{~m}$. By filling of critical goaf before residual mining, $1110 \mathrm{~m}$ goaf filling body of and its sill pillar together constituted the isolated safety belt, which eliminated the mutual interference between residual mining above $1110 \mathrm{~m}$ and normal deep mining ([9]).1190m goaf filling body, crown pillar and upper artificial roof formed isolated safety belt as well, which avoid the open-pit upper 1190m laying restraints on residual mining below ([2]). The key goaf within the range of residual mining is filled and has been effectively controlled, thereby, it avoids the instability of the goaf. For this reason, the work area of residual mining is always in the safe reconstruction environment by pre-filling of the key goaf and collaborative filling of non-key goaf in the process of residual mining([7], [10]).The safe reconstruction environment is effectively managed in the upper, lower horizontal isolated safety belt and central hidden dangers in goaf ([8]).It achieves overall security and stability in the process of residual mining. Key goaf filling is showed as following (Figure $1)$.

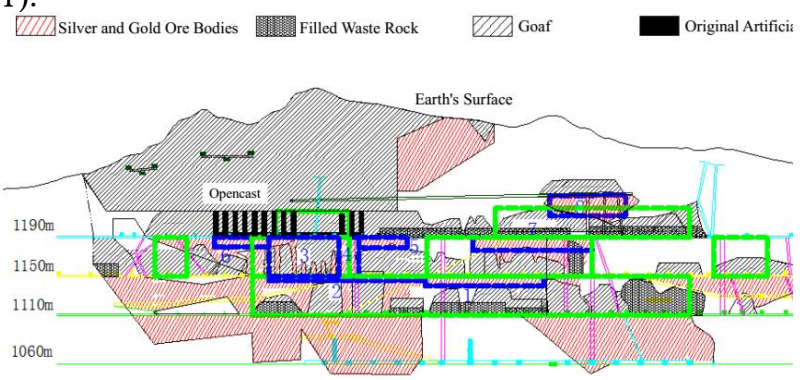

Fig. 1. the longitudinal section of key goaf filling and main mining areas (Note: The green is key goaf filling, the blue is residual mining area.)

\subsection{The Mining Sequence}

According to residual ore conditions and the overall idea of mining technology, main areas of residual ore were conducted by mining division. Residual division and mining sequence were shown as following (Figure 2, Figure 3, Figure 4).

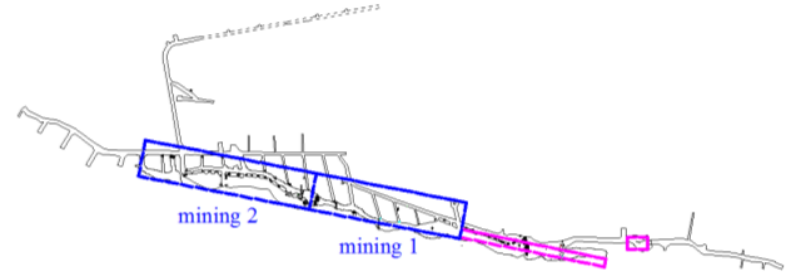

Fig. 2. residual division and weathering sand cemented filling areas in the level of $1110 \mathrm{~m}$

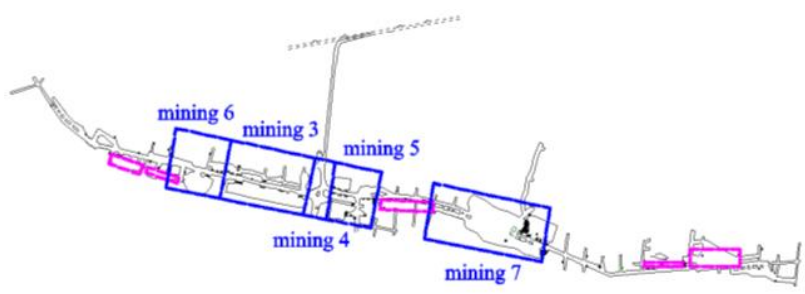

Fig. 3. residual division and weathering sand cemented filling areas in the level of $1150 \mathrm{~m}$

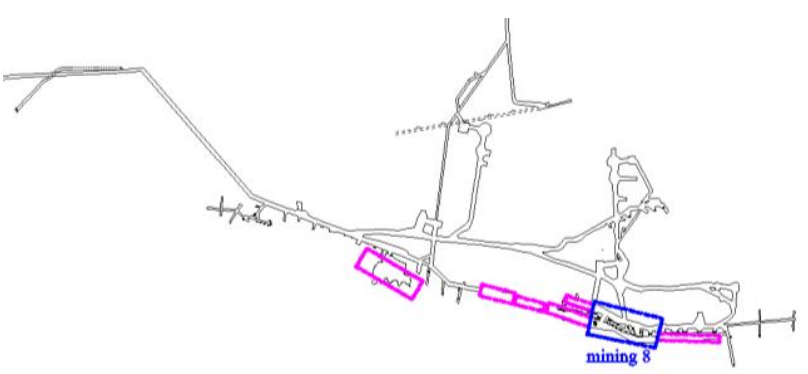

Fig. 4. residual division and weathering sand cemented filling areas in the level of $1190 \mathrm{~m}$

\section{Methods of Residual Ore Mining}

According to the goaf distribution, the state of waste stone filling and types of ore pillar in Niujuan SilverGold Deposit, residual ore were divided into four types. Methods of the residual mining will be separately conducted.

\subsection{Rib Pillar with Waste Rock Cemented Filling on Both Sides of Goafs}

When there was no filling in goaf on both sides of rib pillars, it should be filled with waste rock cemented filling in advance. Rib pillar applies the method of upward horizontal layered filling with pointed pillars (Figure 5).

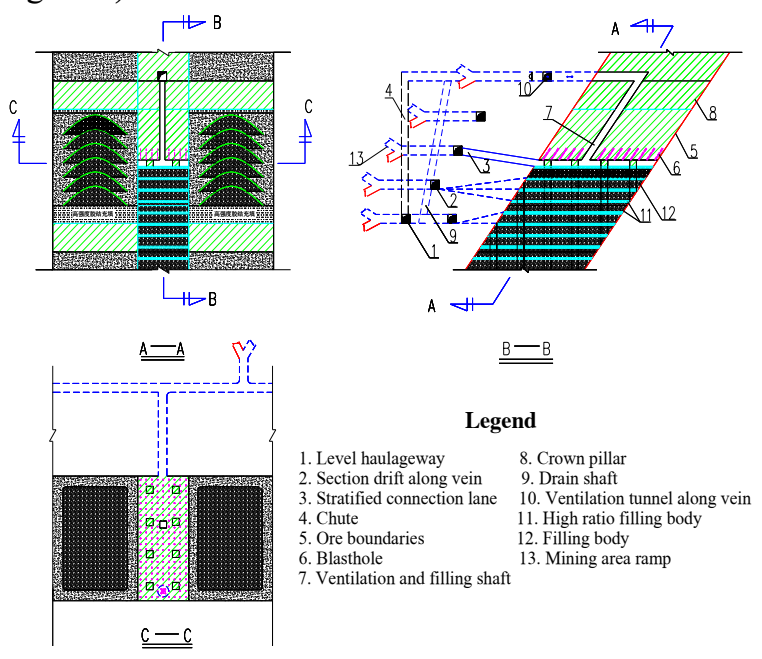

Fig. 5. method of upward horizontal layered filling with pointed pillars 


\subsubsection{Preparation and Cutting}

The surrounding rock on ore body footwall crush. The preparation and cutting engineering was arranged on the hanging wall. Segmented drift along veins were forms through ramps, and then make the construction layered connection way link the stope.

\subsubsection{Mining Technology}

The height of each layer was $3.2 \mathrm{~m}$. Roof height keeping was $4.5 \mathrm{~m}$ and the maximum should not exceed $5 \mathrm{~m}$. It applied shallow-hole drilling, artificial charge and nonelectric initiation systems. After each layer was filled, ore drawing channel of stope was raised by way of capping the bottom, and then turned upward layered stoping in cycles.

\subsubsection{Ore Drawing Transportation}

Ore were discharged from the scraper into the ore-pass, and then were transported by electric locomotive and discharged into main ore-pass.

\subsubsection{Stope Filling}

It adopted waste rock filling. Its top was $0.5 \mathrm{~m}$ high strength filling surface. The excavated waste rock were not carried out of the mine but poured directly into goaf.

\subsubsection{Ventilation}

Fresh air blowed from ramps, segmented along veins drift and access way to the stope. Polluted air went through the ventilation and filling shaft of stope, and then drifted into the upper stage and was discharged by haulage way.

\subsection{Rib Pillars with Waste Rock Filling on Both Sides of Goaf}

When goafs on both sides of rib pillars had waste rock filling, about 1 meter thick wall protection were left on both sides of stope, so as to ensure the stope mining safety and reduce stope dilution (when ore grade was higher, wall protection could not be left, but the rate of dilution on the edge would be higher.) When the method of upward horizontal small layered filling with pointed pillars are applied, for both sides of stopes are dispersion of waste rock filling, the mining height should be controlled within 4 meters.

Mining technology was consistent with section 3.1. However, due to the reduction of layer height, the quantity of preparation and cutting engineering increased slightly. The production capacity of stope decreased, while the wall protection that left on both sides of stope increased mining losses.
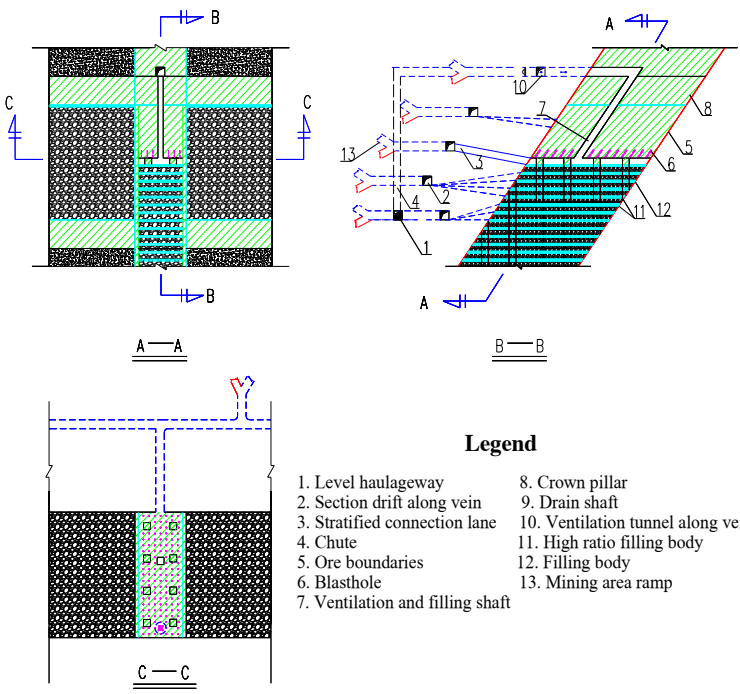

$A \Perp$
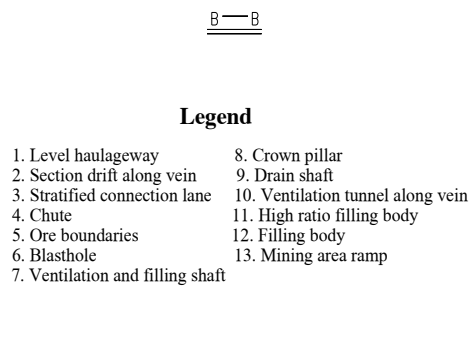

Fig. 6. method of upward horizontal small layered filling with pointed pillars

\subsection{The Crown Pillar with Overlying High Strength of Filling Body}

When goaf above the crown pillar doesn't have waste rock filling, the treatment solution of goaf was selected according to the grade of crown pillar. When the grade of crown pillar was high, high strength cemented filling body of more than $6 \mathrm{~m}$ thickness should be laid at the goaf bottom, and then formed artificial roof of crown pillar for stoping (Figure 7). When the grade of crown pillar was low, waste rock filling is directly applied (Figure 8).

When the crown pillar was overlying high strength of filling body, its stoping scheme should consider matching the external engineering of rib pillars mining. Meanwhile, it should have the features of flexibility and adaptability on stoping of residual ores. Thus, the bottom of the crown pillar applied the method of upward horizontal layered filling. Its stoping technology was similar to section 3.1. The upper $8 \mathrm{~m}$ adopts entrance method of extraction, the entrance width was within $4 \mathrm{~m}$ and its height is $4 \sim 4.5 \mathrm{~m}$. After completion of extraction, roof-contacted filling should be promptly conducted and weathered sand cement filling is applied.

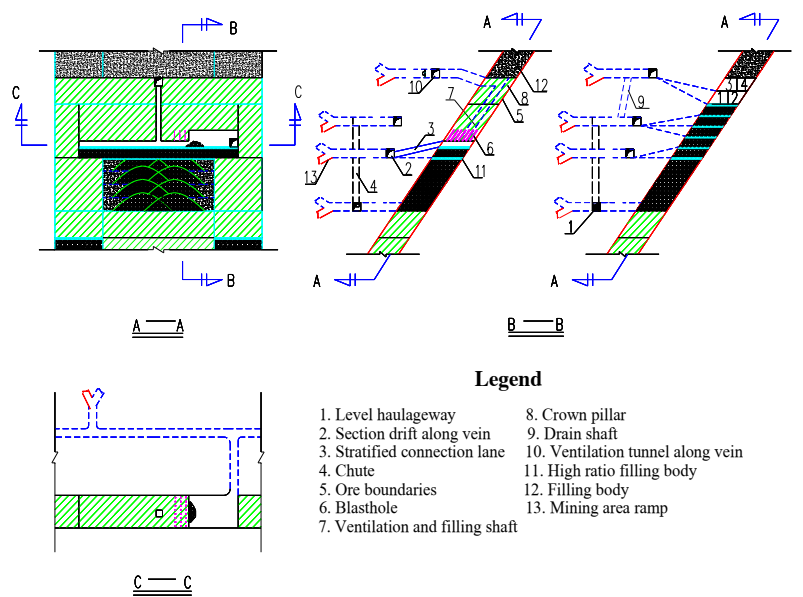

Fig. 7. method of upward horizontal layered filling and entrance filling 


\subsection{The Crown Pillar with Overlying Waste Rock}

When waste rock was overlying crown pillar, the ore body at the bottom of the crown pillar still applied the method of upward horizontal layered filling. The upper part of the crown pillar applied caving method, extruding blasting, conducts ore drawing under overlying rock and applies retreat mining.

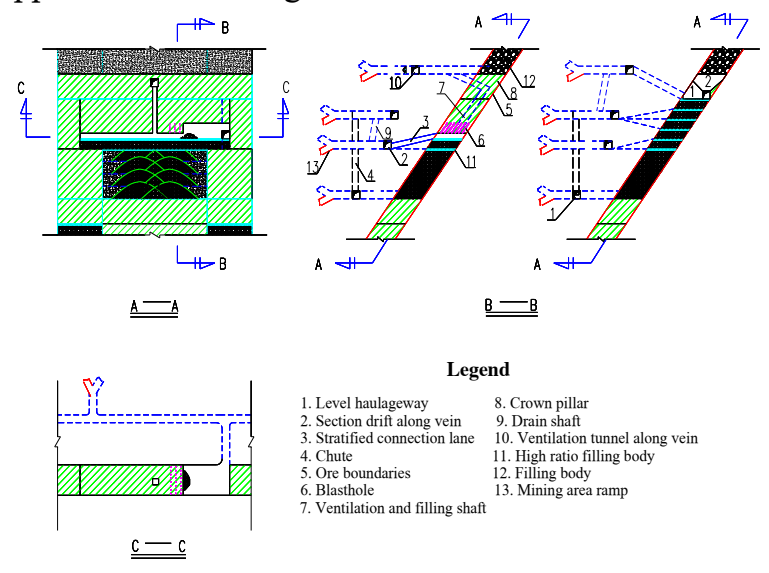

Fig. 8. method of upward horizontal layered filling and caving

The stoping scheme of crown pillar with overlying waste rock and overlying filling body were different. The difference was that only the upper part of $8 \mathrm{~m}$ crown pillar mining method was not the same (Figure 8). Part 1 was the entrance method of mining filling. Part 2 was backward extrusion lateral caving.

\section{The Filling Scheme of Goaf}

The waste rock were mainly from surface and underground excavation. They were transshipped from pass of waste rock to goafs by trackless loading equipment. Cemented filling mainly applied weathered sand and cement by surface filling system.

According to goaf treatment and residual ore mining technology solution, the goaf need filling were divided into two ways: waste rock + medium high strength with weathered sand cemented filling, waste rock + low strength with weathered sand cemented filling.

The way of waste rock + medium high strength with weathered sand cemented filling were mainly gathered in the residual ore mining area. The function of cemented filling was included as following.

(1) During the stoping of rib pillars, its neighboring goaf employs waste rock cemented filling. Near side of rib pillar employs medium strength with weathered sand cemented filling. It was ensured that the self-supporting of filling body and bearing the overlying rock layers.

(2) When the grade of crown pillar was high, high strength cemented filling body with $6 \mathrm{~m}$ thickness should be laid at the bottom of goaf, and then makes the stoping of crown pillars under the work environment of artificial roof.

(3) The method of upward horizontal layered filling was waste rock filling + artificial surface. Artificial surface is high strength with weathered sand cemented filling. It should meet the strength requirements of the scraper.

The goaf beyond residual mining area applies waste rock + low strength with weathered sand cemented filling. Only its top applies low strength with weathered sand cemented filling and contacts the roof.

The cemented filling area was showed as following (Figure 2, Figure 3, Figure 4): The blue is weathered sand cemented filling area. The lower part of the carmine is waste rock filling area. Only the top applies low ratio of weathered sand cemented filling.

\section{Safety Technical Measures}

The mine had unstable goafs with a larger number and wide distribution. To avoid potential safety problems, the goafs should be filled timely. However, part of the goafs is still in an unstable state. There was a risk of trans-falling. Therefore, in order to fully guarantee personnel safety in the process of goaf management and residual ore mining, it should conduct stability monitoring in goaf areas and takes appropriate safety measures.

(1) Regional monitoring: It applies the form of micro seismic monitoring, conducts overall grasp of regional stability in goaf area, and then have timely assessment, feedbacks and early warning.

(2) Local monitoring: According to the filling sequence, the goaf are divided into filling work area and awaiting filling area. Among them, work area employs the way of local refinement monitoring (the specific means was to combine the more intensive micro seismic monitoring with surrounding rock convergence monitoring). It precisely controls the stability of the goaf area and relative areas (It's normally goaf and mining pillar within a certain space in filling work areas) that affects its safety, and then guarantee personnel safety during the filling of mining.

(3) Filling safety: The filling is realized by getting through the connection tunnel along vein, and then arranges inclined shaft or filling drilling toward the middle of goaf roof. Workers and filling input should be outside the rock movement range of the lower goaf. During the operation, it should pay close attention to the changes in ore and the data of ground pressure monitoring.

(4) Goaf sealing: Close all channels of awaiting filling goafs to filling work areas and other production areas. Connect goaf with surface or upper old area. Guide shock wave and outpour to harmless area. The goaf area should keep some rock cushions. People were forbidden entering areas near awaiting filling goaf.

(5) Surface monitoring: Subsidence monitoring was conducted on surface hazards and critical facilities. Stability analysis and forecast work were made regularly. Movement and subsidence area were set on surface. People are forbidden entering. 


\section{Conclusion}

Based on goaf, the existing condition and the exploitation status of residual ore in Niujuan Silver-Gold Deposit, the studies on goaf management, residual ore mining and safety technical measures were conducted. The main conclusion are as following:

(1) The way of management in goaf is filling. It mainly focuses on waste rock filling and supplemented with cemented filling.

(2) The filling of key goaf should be completed before residual ore mining. The filling of non-key goaf coordinates with residual ore mining.

(3) To rib pillars with waste stone cemented filling and waste stone filling on both sides of goaf, the method of upward horizontal common layered and small layered filling with pointed pillars are separately employed.

(4) To the crown pillar overlying high strength of filling body and waste rock, the union method of upward horizontal layered filling, with entrance filling and caving are separately employed.

(5) It applies regional and local comprehensive monitoring system with micro seismic, convergence and settlement. The goaf is sealed and shock wave is conducted. It is forbidden to access the dangerous areas.

\section{Acknowledgments}

This research was funded by the National Key Research and Development Program of China (No. 2016YFC0600802).

\section{Reference}

1. FENG J., ZHANG J.X., HUANG Y.L. AND AN T.L.2009. Waste filling technology under condition of complicated geological condition working face. Procedia Earth and Planetary Science, vol. 1, no.1.pp. 1220-1227.

2. GAO W. AND GE M.M.2016. Stability of a coal pillar for strip mining based on an elastic-plastic analysis. International Journal of Rock Mechanics and Mining Sciences, vol. 87, no.5.pp. 23-28.

3. Jaiswal A., Sharma S.K. AND Shrivastva B.K.2004.Numerical modeling study of asymmetry in the induced stresses over coal mine pillars with advancement of the goaf line. International Journal of Rock Mechanics and Mining Sciences, vol. 41, no.5.pp. 859-864.

4. Kushwaha A., Singh S.K., Tewari S. AND Sinha A.2010. Empirical approach for designing of support system in mechanized coal pillar mining. International Journal of Rock Mechanics and Mining Sciences, vol. 47, no.7.pp. 1063-1078.

5. LV S. AND LV S.2011. Research on Governance of Potential Safety Hazard in Da'an Mine Goaf. Procedia Engineering, vol. 26.pp. 351-356.

6. Ma, H.T., WANG, J.A. AND WANG, Y.H.2012. Study on mechanics and domino effect of large- scale goaf cave. Safety Science, vol. 50, no.4.pp. 689-694.

7. Maria F.D., Micale C., Sordi A., Cirulli G. AND Marionni M. 2013. Urban Mining: Quality and quantity of recyclable and recoverable material mechanically and physically extractable from residual waste. Waste Management, vol. 33, no.12.pp. 2594-2599.

8. Mohammad R., Mohammad F.H. AND Abbas M.2015. Development of a time-dependent energy model to calculate the mining-induced stress over gates and pillars. Journal of Rock Mechanics and Geotechnical Engineering, vol. 7, no.3.pp. 306-317.

9. Singh R., Singh S.K., Kushwaha A. AND Sinha A. 2012.Stability of the parting between coal pillar workings in level contiguous seams during depillaring. International Journal of Rock Mechanics and Mining Sciences, vol. 55, no.5.pp. 1-14.

10. TAN J.K. AND GEORGE J.D.ST. 1989.Geomechanics of underground coal mining under very weak overburden rocks at Huntly East Mine, New Zealand. Mining Science and Technology, vol. 9, no.3.pp. 253-265.

11. Unver B. AND Yasitli N.E.2006. Modelling of strata movement with a special reference to caving mechanism in thick seam coal mining. International Journal of Coal Geology, vol. 66, no.4.pp. 227-252.

12. XU P., MAO X.B., ZHANG M.X., ZHOU Y.J. AND YU B.Y.2014. Safety analysis of building foundations over old goaf under additional stress from building load and seismic actions. International Journal of Mining Science and Technology, vol. 24, no.5.pp. 713-718.

13. XIAO, C., ZHENG, H.C., HOU, X.L. AND ZHANG, X.J.2015. A stability study of goaf based on mechanical properties degradation of rock caused by rheological and disturbing loads. International Journal of Mining Science and Technology, vol. 25, no.5.pp. 741-747.

14. XU N.X., ZHANG J.Y., TIAN H., MEI G. AND GE Q.2016. Discrete element modeling of strata and surface movement induced by mining under openpit final slope. International Journal of Rock Mechanics and Mining Sciences, vol. 88, no.5.pp. 61-76.

15. YANG Z.Q. ZHAI S.H., GAO Q. AND LI M.H.2015. Stability analysis of large-scale stope using stage subsequent filling mining method in Sijiaying iron mine. Journal of Rock Mechanics and Geotechnical Engineering, vol. 7, no.1.pp. 87-94.

16. ZHANG D.S., FAN G.W., MA L.Q. WANG A. AND LIU Y.D.2009. Harmony of large-scale underground mining and surface ecological environment protection in desert district - a case study in Shendong mining area, northwest of China. Procedia Earth and Planetary Science, vol. 1, no.1.pp. 1114-1120. 